\title{
Effect of switching from cinacalcet to etelcalcetide on secondary hyperparathyroidism in patients undergoing hemodialysis: an ESCORT trial
}

Yuka Kurokawa', Yusuke Kaida 1*, Takuma Hazama', Yosuke Nakayama', Takaomi Otome', Ryo Shibata', Sakuya Ito', Goh Kodama', Nao Nakamura', Takatoshi Kambe ${ }^{1,2}$, Tomofumi Moriyama ${ }^{1,3}$, Akiko Nagata ${ }^{1,4}$, Aki Minami1 ${ }^{1,5}$, Ryotaro Ando ${ }^{1,6}$, Yoshifumi Wada ${ }^{7}$, Miki Sugiyama ${ }^{1,5}$, Michiaki Usui ${ }^{8}$, Michio Chiba ${ }^{9}$, Atsuo Moriyama ${ }^{3}$, Atsuko Ohara ${ }^{2}$, Hiroshi Miyazaki ${ }^{10}$, Tatsuyuki Kakuma ${ }^{11}$ and Kei Fukami ${ }^{1}$

\begin{abstract}
Background: Etelcalcetide is the first intravenously administered calcimimetic agent used to manage secondary hyperparathyroidism (SHPT) in hemodialysis (HD) patients. We evaluated the safety and efficacy of replacing cinacalcet with etelcalcetide in HD patients.

Methods: One hundred and thirty-three patients HD on cinacalcet were screened, and 93 patients with serumintact parathyroid hormone (iPTH) level of $\geq 60 \mathrm{pg} / \mathrm{mL}$ and serum albumin-corrected calcium (cCa) level of $\geq 8.4$ $\mathrm{mg} / \mathrm{dL}$ were enrolled. The patients were divided into three groups based on the dose of cinacalcet (i.e., 25,50 , and $\geq 75 \mathrm{mg}$ ) and switched to etelcalcetide. Etelcalcetide was administered three times per week for 24 weeks. The primary and secondary endpoints were etelcalcetide conversion dose and etelcalcetide effectiveness for iPTH levels (target range: $60-240 \mathrm{pg} / \mathrm{mL}$ ), respectively.

Results: Of the 68 patients whose iPTH level was within the management target at screening, 60 patients maintained the target level at the end of the study. Among patients whose iPTH level exceeded $240 \mathrm{pg} / \mathrm{mL}$ at screening, it decreased from $401 \pm 246 \mathrm{pg} / \mathrm{mL}$ to $220 \pm 209 \mathrm{pg} / \mathrm{mL}(p<0.001)$ at the end of the study. Among 22 patients with the iPTH level of $\geq 240 \mathrm{pg} / \mathrm{mL}, 17$ achieved the target level. The mean dose of cinacalcet was $41.4 \pm$ $22.2 \mathrm{mg} /$ day and that of etelcalcetide at the end of the study was $6.4 \pm 3.7 \mathrm{mg} / \mathrm{session}$ in all patients. In 45 patients whose iPTH level was within the management target throughout the study and active vitamin D agent and calcium-based phosphate binder doses were constant, the mean dose of cinacalcet was $45.0 \pm 22.4 \mathrm{mg} / \mathrm{day}$ and that of etelcalcetide at the end of the study was $6.1 \pm 3.1 \mathrm{mg} / \mathrm{session}$. The spKt/ $\mathrm{might}$ affect the ratio of etelcalcetide per session to oral cinacalcet per day (45 patients, $p=0.087 ; 90$ patients, $p<0.05$ ) in the generalized linear model. Etelcalcetide-induced severe adverse events were not observed.

(Continued on next page)
\end{abstract}

\footnotetext{
* Correspondence: kaida_yuusuke@kurume-u.ac.jp

'Division of Nephrology, Department of Medicine, Kurume University School

of Medicine, 67 Asahi-machi, Kurume, Fukuoka 830-0011, Japan

Full list of author information is available at the end of the article
}

(c) The Author(s). 2020 Open Access This article is licensed under a Creative Commons Attribution 4.0 International License, which permits use, sharing, adaptation, distribution and reproduction in any medium or format, as long as you give appropriate credit to the original author(s) and the source, provide a link to the Creative Commons licence, and indicate if changes were made. The images or other third party material in this article are included in the article's Creative Commons licence, unless indicated otherwise in a credit line to the material. If material is not included in the article's Creative Commons licence and your intended use is not permitted by statutory regulation or exceeds the permitted use, you will need to obtain permission directly from the copyright holder. To view a copy of this licence, visit http://creativecommons.org/licenses/by/4.0/ The Creative Commons Public Domain Dedication waiver (http://creativecommons.org/publicdomain/zero/1.0/) applies to the data made available in this article, unless otherwise stated in a credit line to the data. 
(Continued from previous page)

Conclusions: This study reports the conversion dose of etelcalcetide and demonstrates its safety and efficacy in HD patients with SHPT previously treated with cinacalcet.

Trial registration: UMIN, UMIN000027637; Registered on June 5, 2017.

Keywords: Cinacalcet, Etelcalcetide, Hemodialysis, Intact-PTH, Secondary hyperparathyroidism

\section{Background}

Secondary hyperparathyroidism (SHPT), a serious hemodialysis (HD) complication, causes bone lesions such as osteitis fibrosa and increases vascular calcification to life-threatening levels [1]. Previous observational studies in patients undergoing dialysis correlated elevated serum levels of phosphorus (P), calcium (Ca), parathyroid hormone (iPTH), and fibroblast growth factor 23 (FGF-23) with death and cardiovascular events [2,3]. At the end of 2012, the proportion of patients with HD whose Ca $(8.4-10.0 \mathrm{mg} / \mathrm{dL}), \mathrm{P}$ (3.5-6.0 $\mathrm{mg} / \mathrm{dL})$, and $\mathrm{iPTH}(60-240 \mathrm{pg} / \mathrm{dL})$ levels were within the target ranges according to the Japanese Clinical Guidelines was $33.1 \%$ in Japan [4]. Moreover, several patients with bone and mineral metabolism markers outside the range recommended by the Kidney Disease Outcomes Quality Initiative (K/DOQI) have been reported [5].

Elevated serum iPTH level stimulates bone resorption, thereby releasing $\mathrm{Ca}$ and $\mathrm{P}$ and leading to not only bone and mineral metabolism-related diseases but also vascular calcification [6], which are strongly associated with increased morbidity and mortality in patients with HD $[3,7,8]$. Thus, the management of $\mathrm{PTH}$ within an appropriate range is important.

Currently, the treatments for SHPT include active vitamin D agents and calcimimetics. The emergence of calcimimetics has led to advances in SHPT treatment. Since 2004, cinacalcet has been marketed in the USA, and this has improved the conformance rate of K/DOQI management target for $\mathrm{iPTH}, \mathrm{Ca}$, and $\mathrm{P}$ in $\mathrm{HD}$ patients with SHPT [9, 10]. Furthermore, despite the beneficial clinical effects of cinacalcet, its use has been limited by gastrointestinal adverse events, including nausea and vomiting. Furthermore, most patients with SHPT require other oral medications to treat associated complications, resulting in poor adherence.

Etelcalcetide, the first intravenously administered calcimimetic agent, substantially reduces the iPTH level, with only a few gastrointestinal symptoms [11-13]. Furthermore, studies have reported relatively few drug interactions and long-term iPTH suppression with etelcalcetide [14, 15]. Moreover, Block GA et al. showed that etelcalcetide is not superior to cinacalcet in terms of gastrointestinal adverse effects and substantially reduces iPTH levels [16]. Owing to the reduced efficacy and adherence of cinacalcet compared with etelcalcetide, switching to etelcalcetide may be more beneficial to patients with a high iPTH level.

There are only a few studies on the benefits of etelcalcetide in CKD-mineral and bone disorder (CKD-MBD), its equivalent converted amounts, and its safety after switching from cinacalcet. Therefore, we conducted a prospective study to determine etelcalcetide conversion dose and assess the safety and efficacy of replacing cinacalcet with etelcalcetide in HD patients with SHPT.

\section{Methods \\ Patients}

This was a multicenter open-labeled study. Japanese HD patients with SHPT (aged > 20 years) were enrolled. The major inclusion criteria were over 24 weeks of cinacalcet treatment, at least 3 months of fixed-dose administration before screening, no change in phosphate binder or activated vitamin $\mathrm{D}$ dosage within 14 days before screening, and no change in dialysis procedure or hemodialysis instrument within 14 days before screening. The spKt/V was more than 1.2. The major exclusion criteria were as follows: serum-corrected calcium (cCa) level of $<8.4 \mathrm{mg}$ / $\mathrm{dL}$ at screening, primary hyperparathyroidism; scheduled parathyroidectomy, parathyroid intervention, or kidney transplant during the study period; serum iPTH level of $<60 \mathrm{pg} / \mathrm{mL}$; poor compliance of cinacalcet; and pregnancy, possibility or plan of pregnancy, and lactation.

This multicenter open-labeled study was conducted in compliance with the International Council for Harmonization ( $\mathrm{ICH}$ - - Good Clinical Practice guidelines and the Declaration of Helsinki. The protocol was approved by the institutional review boards of Kurume University School of Medicine (No: 17001), Yame General Hospital (No: 17-001), Moriyama Clinic of Internal Medicine, Nagata Hospital, Sugi Cardiovascular Hospital, Yamaguchi Saiseikai General Hospital, Wada Cardiovascular Clinic, Usui Clinic, Chiba Naika Jyunkankika, and Miyazakinaika Medical Clinic: Clinical Research Network Fukuoka (No: 17-E06). Written informed consent was obtained from each study site. Furthermore, written informed consent was obtained from all patients before enrollment. This study was funded by Ono Pharmaceutical Co., Ltd (Osaka, Japan). 


\section{Study procedure}

We divided the patients into three groups according to the oral dose of cinacalcet $(25,50$, and $\geq 75 \mathrm{mg} /$ day $)$ and switched to etelcalcetide. Etelcalcetide was administered within 7 days of the last cinacalcet dose and three times per week for 24 weeks. As a starting dose, $5 \mathrm{mg} / \mathrm{session}$ etelcalcetide was administered three times a week. The dose was then appropriately adjusted within the range of $2.5-15 \mathrm{mg} / \mathrm{session}$, three times a week; iPTH and $\mathrm{cCa}$ levels of the patients were monitored. The administration period was set to 6 months (Fig. 1). Varying criteria were used for etelcalcetide dosing. The same dose of etelcalcetide was maintained for over 4 weeks; if the iPTH level was $>240 \mathrm{pg} / \mathrm{mL}$ and cCa level was $\geq 8.4 \mathrm{mg} /$ $\mathrm{dL}$, the etelcalcetide dose was increased at a rate of $2.5-$ $5.0 \mathrm{mg}$. If the iPTH level was $<60 \mathrm{pg} / \mathrm{mL}$ or cCa level was $<8.4 \mathrm{mg} / \mathrm{dL}$, the dose of etelcalcetide was reduced and treatment with active vitamin $\mathrm{D}$ agent and calciumbased phosphate binders (CBPBs) was stopped or adjusted. Other phosphate binders were adjusted to reach the target level of serum $\mathrm{P}(3.5-6.0 \mathrm{mg} / \mathrm{dL})$. The dose adjustment of each medication was left to the discretion of the prescribing physician.

\section{Biochemical and other determinations}

A blood test was performed at the start of dialysis and after 2 days without dialysis. A blood biochemistry test including $\mathrm{iPTH}$ and serum $\mathrm{cCa}$ was performed at screening and at the end of the study. iPTH and serum $P$ levels were measured once every 2 weeks, from the start of the study to week 12 , and once every 4 weeks after week 12 . Serum cCa level was measured every week until week 12, and every 2 weeks after week 12 (Fig. 1). As an exploratory study, FGF-23, bone alkaline phosphatase (BAP), and tartrate-resistant acid phosphatase (TRACP-5b) were measured at screening and at the end of the study. These analyses were performed at the
Special Reference Laboratory (Tokyo, Japan). Serum iPTH level was determined using the electrochemiluminescence immunoassay (Elecsys; Roche Diagnostics, Tokyo, Japan) (reference range, 10-65 pg/ml). FGF-23 was measured using the enzyme-linked immunosorbent assay kit (Kainos, Tokyo, Japan) (reference range, 14.7-40.5 pg/mL), BAP using the chemiluminescence enzyme immunoassay (Access Ostase, Beckman Coulter, Tokyo, Japan) (reference range, $3.7-20.9 \mu \mathrm{g} / \mathrm{L}$ ), and TRACP-5b using the enzyme immunoassay (Osteolinks TRAP-5b, Nittobo Medical, Fukushima, Japan) (reference range, $170-590 \mathrm{mU} / \mathrm{dL}$ for men and 120-420 mU/dL for women). cCa level was calculated using the Payne formula [17].

\section{Endpoints}

The primary endpoints were etelcalcetide dose change and cinacalcet to etelcalcetide conversion safety. To analyze the dose changes in the cinacalcet groups $(25$, 50 , and $\geq 75 \mathrm{mg}$ ), we analyzed etelcalcetide dose variations. In addition, we assessed the relationship of the ratio of etelcalcetide per session to oral cinacalcet per day with clinical factors. Adverse events (AEs) were also recorded. The secondary endpoint was the effectiveness of etelcalcetide, evaluated using the number of patients with $\mathrm{iPTH}$ level in the target range of $60-240 \mathrm{pg} / \mathrm{mL}$. We used the iPTH target range $60-240 \mathrm{pg} / \mathrm{mL}$ as proposed by the Japanese Society for Dialysis Therapy [18]. During the transition, we also analyzed FGF-23 and bone metabolism markers.

\section{Statistical analysis}

Data are presented as mean \pm standard deviation (SD). The efficacy of switching from cinacalcet to etelcalcetide was evaluated using the iPTH level and other clinical measures, based on Wilcoxon signed-rank test. To compare the baseline characteristics of patients among each group, an analysis of variance or Fisher's exact test was

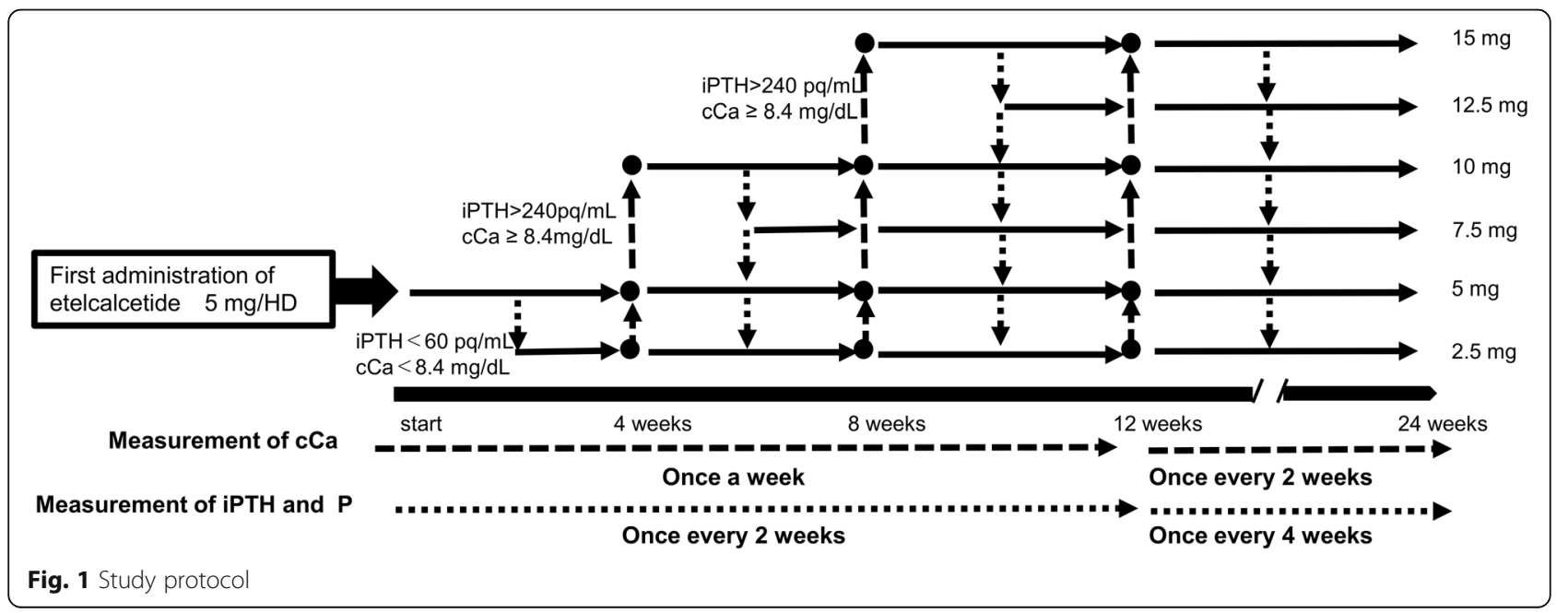


40 patients excluded (didn't meet inclusion criterion)

1 intact parathyroid hormone (iPTH) $<60 \mathrm{pg} / \mathrm{mL}: 11$ patients

2 corrected $\mathrm{Ca}<8.4 \mathrm{mg} / \mathrm{dL}: 19$ patients

$3 \mathrm{iPTH}<60 \mathrm{pg} / \mathrm{mL}$ and corrected $\mathrm{Ca}<8.4 \mathrm{mg} / \mathrm{dL}: 3$ patients

$4 \mathrm{spKt} / \mathrm{V}<1.2 .1$ patients

5 change in cinacalcet or activated vitamin $D$ dosage after screening: 5 patients

6 hospitalization after screening: 1 patients

3 Patients dropped out

(1) Cerebral hemorrhage

(Intestinal perforation

(3) Sepsis due to pyelonephritis

90 patients were analyzed

Fig. 2 Flow diagram of patients in the trial

performed. To determine the independent variables of etelcalcetide per session to oral cinacalcet per day, we performed a generalized linear model including sex and age, duration of dialysis, spKt/V, cCa, P, and iPTH. Results with a $p$ value of $<0.05$ were considered statistically significant. All statistical analyses were performed using SAS software, version 9.4 (SAS Institute, Inc., Cary, NC, USA).

\section{Results}

\section{Patient enrollment}

Patients were enrolled between June 2017 and June 2018. Of the 133 patients, 40 were excluded at screening (cCa $<8.4 \mathrm{mg} / \mathrm{dL}, 19$ patients; iPTH $<60 \mathrm{pg} / \mathrm{mL}, 11$ patients; $\mathrm{cCa}<8.4 \mathrm{mg} / \mathrm{dL}$ and $\mathrm{iPTH}<60 \mathrm{pg} / \mathrm{mL}, 3$ patients; $\mathrm{spKt} / \mathrm{V}<1.2,1$ patient; change in cinacalcet or activated vitamin D dosage after screening, 5 patients, hospitalization

Table 1 Demographic and baseline characteristics of the study patients

\begin{tabular}{|c|c|c|c|c|c|}
\hline Cinacalcet dose before switching & $25 \mathrm{mg} / \mathrm{day}(n=53)$ & $50 \mathrm{mg} / \mathrm{day}(n=18)$ & $\geq 75 \mathrm{mg} /$ day $(n=19)$ & Total $(n=90)$ & $P$ value \\
\hline Female (\%) & $16(30.2)$ & $3(16.7)$ & $8(42.1)$ & $27(30.0)$ & $P=0.227$ \\
\hline Age (year) & $63.6 \pm 8.7$ & $61.6 \pm 13.1$ & $57.8 \pm 10.8$ & $62.0 \pm 10.3$ & $P=0.106$ \\
\hline Dry weight (kg) & $59.2 \pm 11.7$ & $63.6 \pm 17.4$ & $58.7 \pm 11.3$ & $60.0 \pm 12.9$ & $P=0.414$ \\
\hline Systolic blood pressure (mmHg) & $148.7 \pm 25.0$ & $144.8 \pm 22.3$ & $144.5 \pm 18.0$ & $147.0 \pm 23.0$ & $P=0.717$ \\
\hline Duration of dialysis (years) & $15.1 \pm 8.0$ & $13.0 \pm 6.7$ & $16.5 \pm 7.1$ & $15.0 \pm 7.6$ & $P=0.356$ \\
\hline spKt $N$ & $1.7 \pm 0.3$ & $1.6 \pm 0.3$ & $1.7 \pm 0.2$ & $1.7 \pm 0.3$ & $P=0.540$ \\
\hline $\mathrm{cCa}(\mathrm{mg} / \mathrm{dL})$ & $8.97 \pm 0.40$ & $9.07 \pm 0.56$ & $9.24 \pm 0.41$ & $9.05 \pm 0.45$ & $P=0.074$ \\
\hline Phosphate (mg/dL) & $5.18 \pm 1.09$ & $5.64 \pm 1.00$ & $5.48 \pm 1.34$ & $5.34 \pm 1.13$ & $P=0.272$ \\
\hline Intact PTH (pg/mL) & $180 \pm 97$ & $177 \pm 123$ & $289 \pm 301$ & $202 \pm 170$ & $P=0.040$ \\
\hline Alb (g/dL) & $3.7 \pm 0.3$ & $3.8 \pm 0.3$ & $3.8 \pm 0.3$ & $3.8 \pm 0.3$ & $P=0.317$ \\
\hline $\mathrm{Mg}(\mathrm{mg} / \mathrm{dL})$ & $2.0 \pm 0.3$ & $2.6 \pm 0.4$ & $2.6 \pm 0.3$ & $2.5 \pm 0.4$ & $P=0.106$ \\
\hline
\end{tabular}

cCa corrected calcium, Intact PTH Intact parathyroid hormone, Alb albumin, $\mathrm{Mg}$ magnesium 
after screening, 1 patient). Of the remaining 93 patients, three withdrew due to serious AEs and 90 completed the study (Fig. 2).

\section{Clinical characteristics of the patients}

Clinical data of the patients obtained at screening are presented in Table 1 . We enrolled 63 men and 27 women aged $62.0 \pm 10.3$ years, who underwent dialysis for $15.0 \pm 7.6$ years. Oral cinacalcet at doses of 25, 50, and $\geq 75 \mathrm{mg} /$ day was previously administered to 53,18 , and $19(75 \mathrm{mg}(n=16), 100 \mathrm{mg}(n=3))$ patients, respectively. In an ongoing medication compliance questionnaire survey, 80 patients indicated that they took the required dose of medication almost daily (6-7 days a week), 10 patients admitted that they sometimes forgot (4-6 days a week), and none of the patients acknowledged that they frequently forgot (2-3 days a week) or hardly remembered (0-1 day a week). Therefore, the study population exhibited a relatively favorable medication adherence.

\section{Laboratory analysis}

iPTH, serum cCa, and serum P variations in the enrolled patients are shown in Fig. 3. Throughout the study, the iPTH level decreased from $202 \pm 169 \mathrm{pg} / \mathrm{mL}$ to $166 \pm$ $119 \mathrm{pg} / \mathrm{mL}(p=0.051)$, particularly in the $25 \mathrm{mg}$ group $(p=0.005)$. The serum cCa level decreased from $9.05 \pm$ $0.45 \mathrm{mg} / \mathrm{dL}$ to $8.74 \pm 0.52 \mathrm{mg} / \mathrm{dL}(p<0.001)$, especially in the $25 \mathrm{mg}$ and $\geq 75 \mathrm{mg}$ groups $(p<0.001, p=0.002$, respectively). The serum $P$ level showed no significant change $(5.34 \pm 1.13 \mathrm{mg} / \mathrm{dL}$ to $5.23 \pm 1.33 \mathrm{mg} / \mathrm{dL})(p=$ $0.314)$.

The iPTH level in some patients (68) was $60-240 \mathrm{pg} / \mathrm{mL}$ at screening, whereas that in some patients (22) exceeded $240 \mathrm{pg} / \mathrm{mL}$. These 68 patients showed no significant change in the iPTH level (from $138 \pm 47 \mathrm{pg} / \mathrm{mL}$ at screening to 149 $\pm 63 \mathrm{pg} / \mathrm{mL})(p=0.106$; Fig. 4): 60 (88.2\%) maintained the target level $(60-240 \mathrm{pg} / \mathrm{mL}), 5$ exceeded $240 \mathrm{pg} / \mathrm{mL}$, and 3 dropped below $60 \mathrm{pg} / \mathrm{mL}$ (Table 2).

In the 22 patients with the iPTH level of $240 \mathrm{pg} / \mathrm{mL}$ at screening, the iPTH level significantly decreased from 401 $\pm 246 \mathrm{pg} / \mathrm{mL}$ to $220 \pm 209 \mathrm{pg} / \mathrm{mL}(p<0.001)$ (Fig. 4). In 17 $(77.3 \%)$ patients, the target iPTH level was achieved, and in 5 patients, the iPTH level remained above $240 \mathrm{pg} / \mathrm{mL}$ (Table 2).

\section{Etelcalcetide dose changes}

In $45 / 90$ patients ( $25 \mathrm{mg}: n=22,50 \mathrm{mg}: n=11, \geq 75 \mathrm{mg}$ : $n=12)$, the iPTH level was within the target $(60-240$ $\mathrm{pg} / \mathrm{mL}$ ) throughout the study, and the doses of active vitamin $\mathrm{D}$ and CBPBs were the same before and after the study. In these 45 patients, the mean dose of cinacalcet was $45.0 \pm 22.4 \mathrm{mg} /$ day and that of etelcalcetide was $6.1 \pm 3.1 \mathrm{mg} / \mathrm{session}$, at the end of the study. The ratio
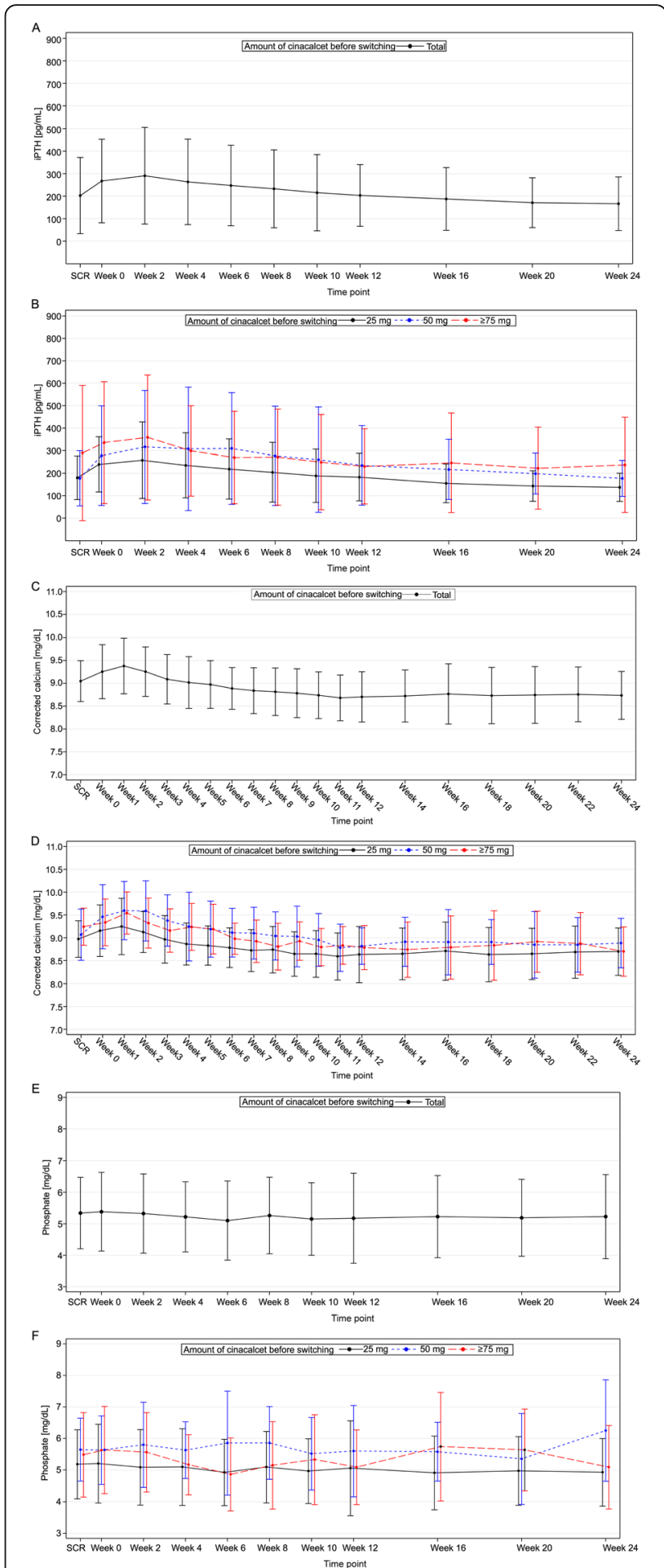

Fig. 3 Parathyroid hormone, calcium, and phosphate levels in patients by study week. a Serum-intact parathyroid hormone levels. b Serum-intact parathyroid hormone levels in each group $(25,50$, and $\geq 75 \mathrm{mg}$ ). c Serum-corrected calcium levels. d Serum-corrected calcium levels in each group (25,50, and $\geq 75 \mathrm{mg})$. e Serum phosphate levels. $\mathbf{f}$ Serum phosphate levels in each group $(25 \mathrm{mg}$, $50 \mathrm{mg}$, $\geq 75 \mathrm{mg}$ ). Data markers indicate the mean and error bars indicate $95 \%$ confidence intervals 


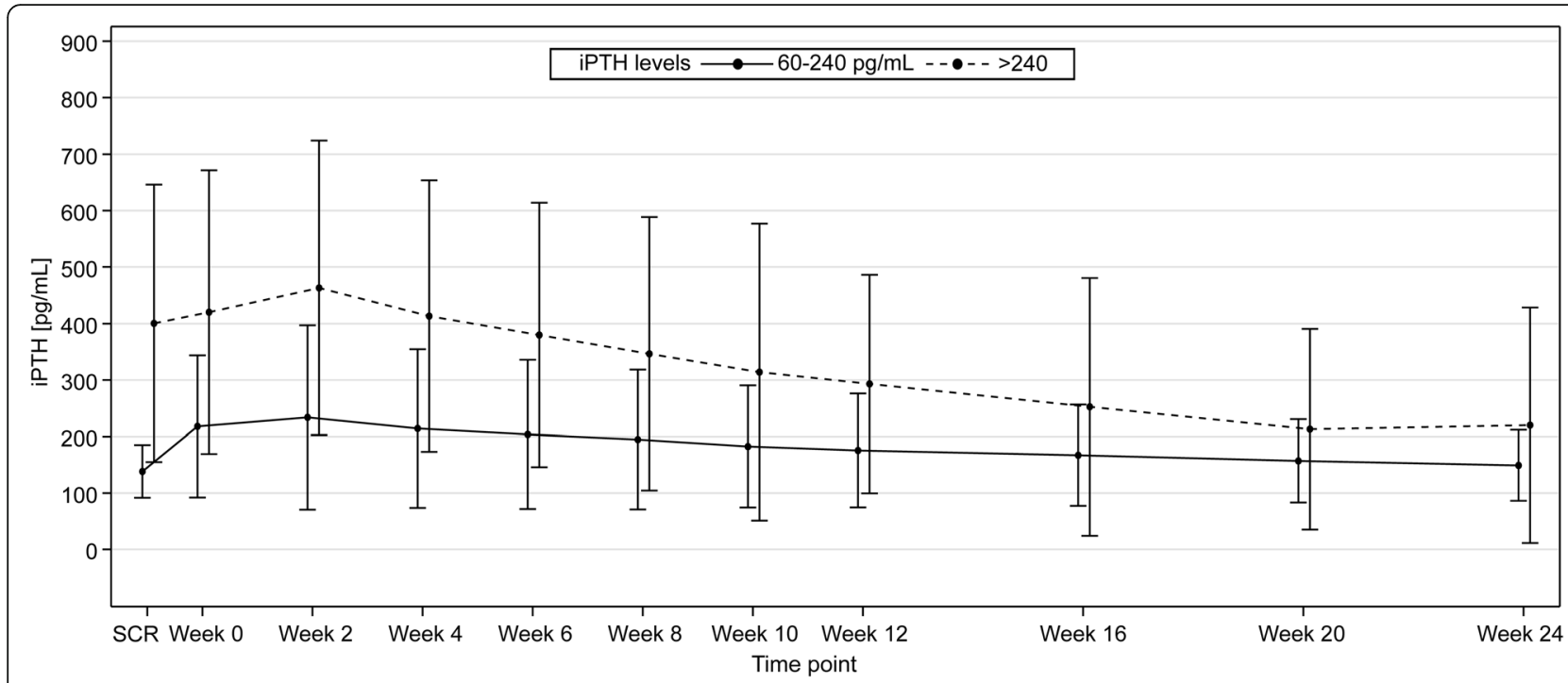

Fig. 4 Intact parathyroid hormone levels in patients of the controlled and uncontrolled groups by study week. Controlled group: intact PTH 60$240 \mathrm{pg} / \mathrm{mL}$, uncontrolled group: intact PTH $>240 \mathrm{pg} / \mathrm{mL}$. Data markers indicate the mean and error bars indicate $95 \%$ confidence interval

of etelcalcetide per session to oral cinacalcet per day was approximately $0.16 \pm 0.09$. When the spKt/V increased by 1.0, the ratio of etelcalcetide per session to oral cinacalcet per day tended to increase by $0.54(p=0.087)$ in these 45 patients (Table 3 ). For the 45 patients, in the $25 \mathrm{mg}$ group, the starting dose was $5 \mathrm{mg} / \mathrm{session}$, which was temporarily reduced to $4.7 \pm 0.9 \mathrm{mg} / \mathrm{session}$ at week 4 and increased to $5.2 \pm 2.3 \mathrm{mg} / \mathrm{session}$ at week 24 (Fig. 5). In the $50 \mathrm{mg}$ group, a dose of $5 \mathrm{mg} / \mathrm{session}$ was maintained until week 4 and increased to $5.5 \pm 1.9 \mathrm{mg} / \mathrm{session}$ from week 6 (Fig. 5). In $\geq 75 \mathrm{mg}$ group, the dose was gradually increased from $5 \mathrm{mg} /$ session to $8.1 \pm 4.3 \mathrm{mg} /$ session at week 24 (Fig. 5). In the $25 \mathrm{mg}$ group, the dose was 5 $\mathrm{mg} /$ session in 13/22 (59.1\%) patients; the dose was reduced in $5(22.7 \%)$ and increased in 4 (18.2 \%) patients. In the $50 \mathrm{mg}$ group, the dose was maintained at $5 \mathrm{mg} / \mathrm{ses}-$ sion in 8 of 11 (72.7 \%) patients, reduced in one (9.1\%), and increased in $2(18.2 \%)$ patients. In the group of patients taking $\geq 75 \mathrm{mg}$, the dose of $5 \mathrm{mg} / \mathrm{session}$ was maintained in 6/12 (50 \%) patients and increased in $6(50 \%)$ patients (Table 4). In 90 patients, the mean dose of cinacalcet was $41.4 \pm 22.2 \mathrm{mg} /$ day and that of etelcalcetide was $6.4 \pm 3.7 \mathrm{mg} / \mathrm{session}$; the ratio of etelcalcetide per session

Table 2 Distribution of intact PTH before and after the study ( $n$ $=90$ )

\begin{tabular}{|c|c|c|c|c|}
\hline \multirow{2}{*}{$\begin{array}{l}\text { iPTH before } \\
\text { switching }\end{array}$} & \multicolumn{3}{|c|}{ iPTH at week 24 after switching } & \multirow[t]{2}{*}{ Total } \\
\hline & $<60 \mathrm{pg} / \mathrm{mL}$ & $60-240 \mathrm{pg} / \mathrm{mL}$ & $>240 \mathrm{pg} / \mathrm{mL}$ & \\
\hline $60-240 \mathrm{pg} / \mathrm{mL}$ & 3 & 60 & 5 & 68 \\
\hline$>240 \mathrm{pg} / \mathrm{mL}$ & 0 & 17 & 5 & 22 \\
\hline Total & 3 & 77 & 10 & 90 \\
\hline
\end{tabular}

to oral cinacalcet per day was approximately $0.18 \pm 0.12$, at the end of the study. When the spKt/V increased by 1.0 , the ratio of etelcalcetide per session to oral cinacalcet per day increased by $0.58(p<0.05)$ in 90 patients (Table 3).

\section{Changes in the doses of medications}

Active vitamin D was used in $83 / 90$ patients, which increased to $85 / 90$ at week 24 , and the dose was increased in 20 and decreased in 7 patients. CBPBs were used in $46 / 90$ patients, which increased to $48 / 90$ at week 24 , and the dose was increased in 9 and decreased in 4 patients. The dose changes for the other phosphate binders are presented in Table 5.

\section{Exploratory endpoints}

FGF-23 significantly decreased from $9115 \pm 11435 \mathrm{pg} /$ $\mathrm{mL}$ to $7591 \pm 9322 \mathrm{pg} / \mathrm{mL}$ at week $24(p=0.009)$. Furthermore, both BAP and TRACP-5b significantly decreased $(16.0 \pm 7.0 \mu \mathrm{g} / \mathrm{L}$ vs. $13.8 \pm 5.8 \mu \mathrm{g} / \mathrm{L}(p<0.001)$ and $580 \pm 292 \mathrm{mU} / \mathrm{dL}$ vs. $405 \pm 229 \mathrm{mU} / \mathrm{dL}(p<0.001)$, respectively) (Supplementary Table 1).

\section{Adverse events}

AEs were observed in 51/93 patients when cinacalcet was switched to etelcalcetide. Three patients experienced mild AEs associated with etelcalcetide during the study. All AEs were mild (Table 6). There were no new gastrointestinal symptoms associated with etelcalcetide. The AEs in three patients who dropped out of the study (cerebral hemorrhage, sepsis, and small intestinal perforation) were not related to etelcalcetide. AEs unrelated to 
Table 3 The relationship of the ratio of etelcalcetide per session to oral cinacalcet per day with clinical factors

\begin{tabular}{|c|c|c|c|c|}
\hline & \multicolumn{2}{|l|}{45 patients } & \multicolumn{2}{|l|}{90 patients } \\
\hline & Exp (estimate) & $p$ value & Exp (estimate) & $p$ value \\
\hline Age & 1.02 & 0.919 & 1.08 & 0.642 \\
\hline Sex & 1.01 & 0.199 & 1.01 & 0.071 \\
\hline Duration of dialysis & 0.74 & 0.147 & 0.81 & 0.221 \\
\hline spKt/N & 0.54 & 0.087 & 0.58 & $<0.05$ \\
\hline $\mathrm{cCa}$ & 1.00 & 0.989 & 0.96 & 0.779 \\
\hline$P$ & 1.01 & 0.904 & 0.97 & 0.642 \\
\hline iPTH & 1.00 & 0.909 & 1.00 & 0.674 \\
\hline
\end{tabular}

45 patients with intact PTH levels within the management target at screening and at the end of the study and with constant vitamin D agent and calcium-based phosphate binder doses

the medications $(\geq 5 \%)$ included shunt problems (20.4\%), cold (20.4\%), and lower back pain (6.5\%). During the study, the cCa level was $<8.4 \mathrm{mg} / \mathrm{dL}$ in $50(55.6 \%)$ patients (25 mg: $n=33,50 \mathrm{mg}: n=8$, and $\geq 75 \mathrm{mg}: n=$ 9 ); among them, the cCa level was $<7.5 \mathrm{mg} / \mathrm{dL}$ in seven patients (7.8\%) (25 mg: $n=4,50 \mathrm{mg}: n=1$, and $\geq 75 \mathrm{mg}: n=2$ ). However, all cases were controlled with etelcalcetide dose reduction and treatment with active vitamin D and CBPBs. Etelcalcetide treatment was ceased in one patient, because the iPTH level decreased below $60 \mathrm{pg} / \mathrm{mL}$.

\section{Discussion}

In this ESCORT trial, we aimed to determine the conversion dose of etelcalcetide and assess its safety and efficacy in HD patients with SHPT previously treated with cinacalcet.
A head-to-head study, in which cinacalcet $51.4 \mathrm{mg} /$ day was switched to etelcalcetide $5 \mathrm{mg} / \mathrm{session}$, reported a slightly stronger effect for etelcalcetide [16]. Xipell et al. suggested the following conversion formula for etelcalcetide $\mathrm{mg} / \mathrm{session}=0.111 \times$ cinacalcet $\mathrm{mg} / \mathrm{day}+0.96$. Unlike a previous study [19], we analyzed dose conversion in 45 patients with iPTH levels maintained between 60 and $240 \mathrm{pg} / \mathrm{mL}$ throughout the study period and maintained constant doses of active vitamin D and CBPBs. Consequently, our study could provide a more accurate conversion of cinacalcet and etelcalcetide than previous studies. Cinacalcet was administered at a dose of $45.0 \pm$ $22.4 \mathrm{mg} /$ day to these 45 patients before etelcalcetide at a dose of $6.1 \pm 3.1 \mathrm{mg} / \mathrm{session}$ at the end of the study. Among these 45 patients with iPTH levels of $60-240 \mathrm{pg} /$ $\mathrm{mg}, 18 / 22$ patients in the $25 \mathrm{mg}$ cinacalcet group received $\leq 5 \mathrm{mg} / \mathrm{session}$ etelcalcetide and required no increase in dose. In the $50 \mathrm{mg}$ cinacalcet group, a dose of

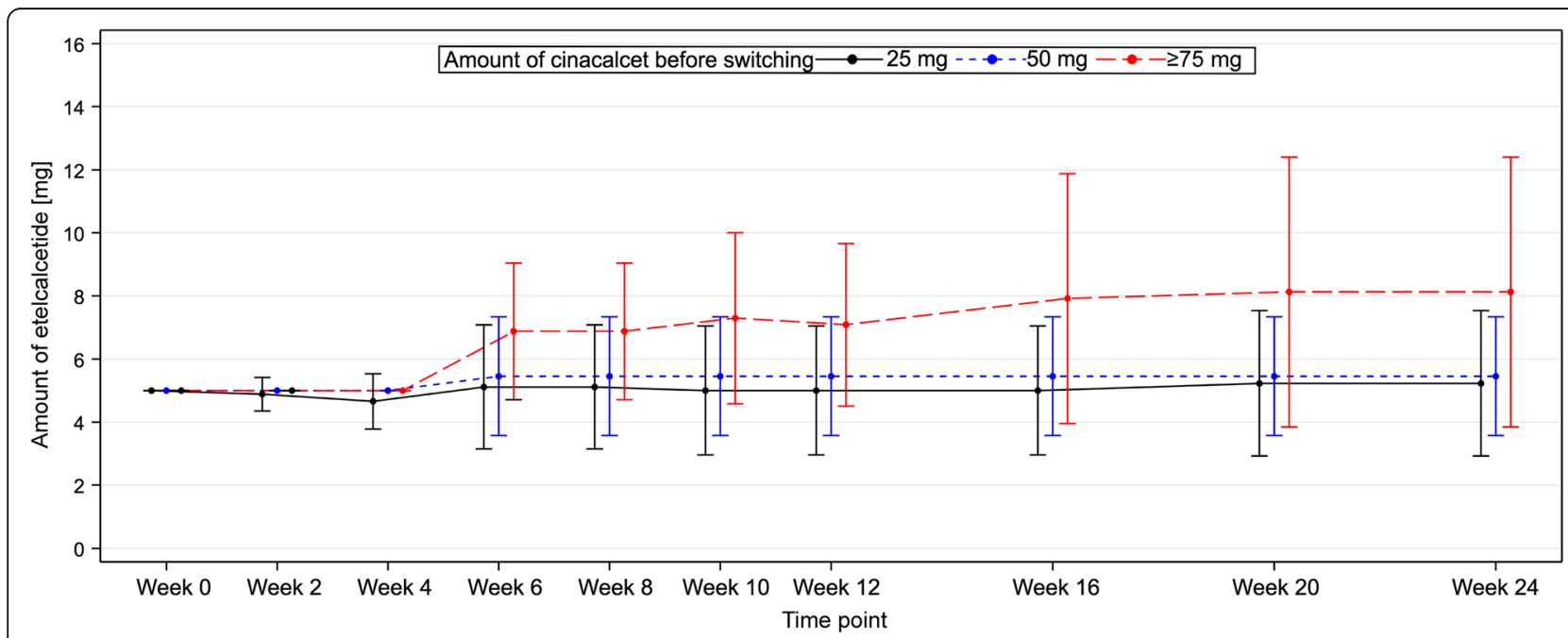

Fig. 5 Changes in the dose of etelcalcetide during the study in each dose group. The doses were 25, 50, and $\geq 75 \mathrm{mg}(n=45)$. For patients with intact PTH levels within the management target at screening and at the end of the study, the same doses of vitamin $D$ agent and calcium-based phosphate binder were selected 
Table 4 Distribution of etelcalcetide hydrochloride at the end of the study

\begin{tabular}{|c|c|c|c|c|c|c|c|c|}
\hline \multirow[b]{2}{*}{ Dose of cinacalcet before switching } & \multicolumn{7}{|c|}{ Dose of etelcalcetide at week 24 after switching } & \multirow[b]{2}{*}{ Total } \\
\hline & $0 \mathrm{mg}$ & $2.5 \mathrm{mg}$ & $5 \mathrm{mg}$ & $7.5 \mathrm{mg}$ & $10 \mathrm{mg}$ & $12.5 \mathrm{mg}$ & $15 \mathrm{mg}$ & \\
\hline $25 \mathrm{mg}$ & 0 & 5 & 13 & 1 & 3 & 0 & 0 & 22 \\
\hline $50 \mathrm{mg}$ & 0 & 1 & 8 & 1 & 1 & 0 & 0 & 11 \\
\hline$\geq 75 \mathrm{mg}$ & 0 & 0 & 6 & 3 & 0 & 0 & 3 & 12 \\
\hline Total & 0 & 6 & 27 & 5 & 4 & 0 & 3 & 45 \\
\hline
\end{tabular}

$5 \mathrm{mg} /$ session was maintained in 8/11 (72.7\%) patients. None of the patients in the $\geq 75 \mathrm{mg}$ cinacalcet group required a dose reduction and 50\% required a dose elevation.

The mean etelcalcetide dose used at the end of the study per group was $5.2 \pm 2.3 \mathrm{mg} /$ session $(25 \mathrm{mg}$ cinacalcet group), $5.5 \pm 1.9 \mathrm{mg} / \mathrm{session}$ ( $50 \mathrm{mg}$ cinacalcet group), and $8.1 \pm 4.3 \mathrm{mg} / \mathrm{session}$ ( $\geq 75 \mathrm{mg}$ cinacalcet group). Consequently, for patients taking $50 \mathrm{mg}$ cinacalcet, the initial etelcalcetide dose of $5 \mathrm{mg} / \mathrm{session}$ was optimal during conversion. However, in the $\geq 75 \mathrm{mg}$ cinacalcet group, the initial etelcalcetide dose was insufficient in $50 \%$ of the patients, and a dose elevation was recommended. In the $25 \mathrm{mg}$ group, only a few patients required a dose elevation, and most patients received less than $5 \mathrm{mg} / \mathrm{session}$, suggesting the need for a lower initial dose. According to Xipell et al. [19], the calculated dose of etelcalcetide used in the $25 \mathrm{mg}$ cinacalcet group was $3.74 \mathrm{mg} / \mathrm{session}$, lower than that in the present study. This may be due to the variability in the initial dose of etelcalcetide used by Xipell et al., as it was based on the prior dose of cinacalcet. However, in this study, the initial dose of etelcalcetide was $5 \mathrm{mg} / \mathrm{session}$, as recommended in the package insert. Xipell et al. started etelcalcetide at a dose of $2.5 \mathrm{mg} / \mathrm{session}$ in the $30 \mathrm{mg}$ cinacalcet group. In the $25 \mathrm{mg}$ cinacalcet group, reducing the dose to $2.5 \mathrm{mg} / \mathrm{session}$ may also be effective.

In this study, the ratio of etelcalcetide per session to oral cinacalcet per day increased with the increase in the spKt/V. Etelcalcetide was primarily cleared by HD, with approximately $60 \%$ of the administered dose eliminated in dialysate. Minor amounts were excreted in urine and feces [20]. Most patients enrolled in our study did not have urine output; it is likely that the excretion of etelcalcetide is mostly through hemodialysis. Therefore, among patients with high hemodialysis efficiency, the required amount of etelcalcetide may have increased due to the increased excretion of etelcalcetide. When switching from cinacalcet to etelcalcetide, hemodialysis efficiency should be considered in dose adjustment. The fact that there was no significant result among the 45 patients was likely due to the small number of patients.

The findings of this study suggest that switching to etelcalcetide when the iPTH level is $>240 \mathrm{pg} / \mathrm{mL}$ can help maintain the iPTH level within the reference range. Particularly, in the poorly controlled group (iPTH $>240$ $\mathrm{pg} / \mathrm{mL}), 17 / 22(77.3 \%)$ patients achieved the reference iPTH level, suggesting that etelcalcetide effectively decreases the iPTH level. It has been reported that etelcalcetide can decrease the iPTH level better than cinacalcet

Table $\mathbf{5}$ List of SHPT medication changes before and after the study

\begin{tabular}{|c|c|c|c|c|c|}
\hline \multirow[b]{2}{*}{ SHPT-related agent } & \multirow[b]{2}{*}{ Time } & \multicolumn{4}{|c|}{ Dose of cinacalcet hydrochloride before switching } \\
\hline & & $25 \mathrm{mg}$ & $50 \mathrm{mg}$ & $\geq 75 \mathrm{mg}$ & Total \\
\hline \multirow[t]{2}{*}{ Active vitamin D agent } & SCR & $48(90.6)$ & $18(100.0)$ & $17(89.5)$ & $83(92.2)$ \\
\hline & 24 weeks & $50(94.3)$ & $17(94.4)$ & $18(94.7)$ & $85(94.4)$ \\
\hline \multirow[t]{2}{*}{ Ca-based phosphate binder } & SCR & $30(56.6)$ & $9(50.0)$ & $7(36.8)$ & $46(51.1)$ \\
\hline & 24 weeks & $33(62.3)$ & $9(50.0)$ & $6(31.6)$ & $48(53.3)$ \\
\hline \multirow[t]{2}{*}{ Lanthanum carbonate } & $S C R$ & $37(69.8)$ & $14(77.8)$ & $15(78.9)$ & $66(73.3)$ \\
\hline & 24 Weeks & $34(64.2)$ & $14(77.8)$ & $13(68.4)$ & $61(67.8)$ \\
\hline \multirow[t]{2}{*}{ Sevelamer } & SCR & $14(26.4)$ & $8(44.4)$ & $7(36.8)$ & $29(32.2)$ \\
\hline & 24 weeks & $12(22.6)$ & $7(38.9)$ & $7(36.8)$ & $26(28.9)$ \\
\hline \multirow[t]{2}{*}{ Iron-based phosphate binder } & SCR & $14(26.4)$ & $2(11.1)$ & $7(36.8)$ & $23(25.6)$ \\
\hline & 24 weeks & $12(22.6)$ & $2(11.1)$ & 6 (31.6) & $20(22.2)$ \\
\hline \multirow[t]{2}{*}{ Bixalomer } & SCR & $6(11.3)$ & $1(5.6)$ & 1 ( 5.3) & $8(8.9)$ \\
\hline & 24 weeks & $5(9.4)$ & $1(5.6)$ & $1(5.3)$ & $7(7.8)$ \\
\hline
\end{tabular}


Table 6 Adverse effects

\begin{tabular}{|c|c|c|c|c|c|c|}
\hline \multirow[b]{3}{*}{ Adverse effects } & \multicolumn{6}{|l|}{ Severity } \\
\hline & \multicolumn{2}{|l|}{ Mild } & \multicolumn{2}{|l|}{ Moderate } & \multicolumn{2}{|l|}{ Severe } \\
\hline & Number & Number of patients (\%) & Number & Number of patients (\%) & Number & Number of patients (\%) \\
\hline All & 3 & $2(2.2)$ & 0 & $0(0.0)$ & 0 & $0(0.0)$ \\
\hline Myocardial injury & 1 & $1(1.1)$ & 0 & $0(0.0)$ & 0 & $0(0.0)$ \\
\hline Angina & 1 & $1(1.1)$ & 0 & $0(0.0)$ & 0 & $0(0.0)$ \\
\hline $\begin{array}{l}\text { General/systemic disorder and } \\
\text { administration-site conditions }\end{array}$ & 1 & $1(1.1)$ & 0 & $0(0.0)$ & 0 & $0(0.0)$ \\
\hline Discomfort & 1 & $1(1.1)$ & 0 & $0(0.0)$ & 0 & $0(0.0)$ \\
\hline Infection and parasitic disease & 1 & $1(1.1)$ & 0 & $0(0.0)$ & 0 & $0(0.0)$ \\
\hline Skin infection & 1 & $1(1.1)$ & 0 & $0(0.0)$ & 0 & $0(0.0)$ \\
\hline
\end{tabular}

and that it is more effective in patients with the abovemanagement target iPTH level taking a high dose of cinacalcet [16]. In some poorly controlled cases, owing to gastrointestinal symptoms caused by cinacalcet, oral medication adherence is a problem. Therefore, switching to intravenously administered agents such as etelcalcetide may be useful in patients with poorly controlled SHPT.

The overall safety and tolerability of etelcalcetide and cinacalcet are similar [16]. In the present study, no significant differences in gastrointestinal AEs including vomiting and nausea were observed. The study comprised patients who safely received cinacalcet, which may have resulted in only a few new gastrointestinal AEs. Hypocalcemia is known to be caused by etelcalcetide. Here, the cCa levels decreased below $8.4 \mathrm{mg} / \mathrm{dL}$ in over $50 \%$ of the patients leading to etelcalcetide dose reduction and active vitamin $\mathrm{D}$ and CPBP dose adjustment. In seven patients, the $\mathrm{cCa}$ level decreased below $7.5 \mathrm{mg} / \mathrm{dL}$ during the study, the level at which etelcalcetide treatment would normally be ceased. As hypocalcemia was not an observed symptom, etelcalcetide dose reduction and active vitamin $\mathrm{D}$ and CBPB dose elevation were left to the discretion of the prescribing physician, and drug withdrawal was avoided. Therefore, hypocalcemia should be considered when replacing cinacalcet. After switching from cinacalcet $25 \mathrm{mg}$, $33 / 53$ patients showed a cCa level of $<8.4 \mathrm{mg} / \mathrm{dL}$. Furthermore, the cCa level significantly decreased in 45 patients with the reference iPTH level, and the requirement for active vitamin D and CBPB treatment suggested that etelcalcetide decreases the $\mathrm{Ca}$ level more than cinacalcet. Consequently, the $\mathrm{Ca}$ level should be closely monitored when switching to etelcalcetide.

The present study had some limitations: not placebocontrolled, had a small number of patients, possible presence of attrition bias, and included only Japanese patients, which may affect the generalizability of the results. In addition, the disease activity of SHPT can be altered during the 24-week study period. Therefore, the prescribed doses at different time points might not be directly compared. This drawback can be solved by conducting a two-arm comparative or a cross-over trial. Therefore, further studies are needed.

\section{Conclusions}

We determined the conversion dose as well as the safety and efficacy of switching from cinacalcet to etelcalcetide in HD patients with SHPT. Our findings provide a basis for understanding the effects and implications of switching from cinacalcet to etelcalcetide.

\section{Supplementary Information}

The online version contains supplementary material available at https://doi. org/10.1186/s41100-020-00310-y.

Additional file 1: Supplementary Table S1

\section{Abbreviations}

AE: Adverse event; BAP: Bone alkaline phosphatase; Ca: Calcium;

cCa: Corrected calcium; CBPB: Calcium-based phosphate binder; CKDMBD: Chronic kidney disease-mineral and bone disorder; FGF-23: Fibroblast growth factor 23; HD: Hemodialysis; iPTH: Intact PTH; KDOQI: Kidney Disease Outcomes Quality Initiative; P: Phosphorus; SHPT: Secondary

hyperparathyroidism; TRACP-5b: Tartrate-resistant acid phosphatase

\section{Acknowledgements}

The authors acknowledge the following investigators: Aki Kojima, Kaoru Nakano, Saori Kubo, Ayako Chikasue, Yuri Kumabe, Junko Yano, Yoshimi Takamiya, Hirotane Chiba, Chie Kishi, and Ryutaro Hidaka. This study was funded by Ono Pharmaceutical Co., Ltd.

\section{Authors' contributions}

Y. Kurokawa., Y. Kaida, and KF prepared the manuscript. Y. Kurokawa, Y. Kaida, TH, YN, TO, RS, SI, GK, NN, TK, TM, AN, RA, YW, MS, MU, MC, AM, AO, and HM collected the clinical data. TK conducted the statistical analyses. All authors agreed to be accountable for all aspects of the work and to ensure that questions related to the accuracy of any part of the work are appropriately resolved. The authors read and approved the final manuscript.

Funding

This study was funded by Ono Pharmaceutical Co., Ltd. (Osaka, Japan).

Availability of data and materials

Please contact the corresponding author for data requests. If the request is valid, we will share our data. 


\section{Ethics approval and consent to participate}

This multicenter open-labeled study was conducted in conformity with the International Council for Harmonization (ICH)—Good Clinical Practice guidelines and the Declaration of Helsinki. The protocol was approved by the institutional review boards of Kurume University School of Medicine (No: 17001), Yame General Hospital (No: 17-001), Moriyama Clinic of Internal Medicine, Nagata Hospital, Sugi Cardiovascular Hospital, Yamaguchi Saiseikai General Hospital, Wada Cardiovascular Clinic, Usui Clinic, Chiba Naika Jyunkankika, and Miyazakinaika Medical Clinic: Clinical Research Network Fukuoka (No: 17E06). This study has been registered in the University Hospital Medical Information Network clinical trials database (UMIN 000027637).

\section{Consent for publication}

Written informed consent was obtained from all patients before enrollment.

\section{Competing interests}

KF, Y. Kaida, and YN received consultant fees from Ono Pharmaceutical Co., Ltd. and Kyowa Hakko Kirin. Y. Kurokawa received consultant fees from Ono Pharmaceutical Co., Ltd. RS, SI, and TM received consultant fees from Kyowa Hakko Kirin. The others authors declare that they have no competing interests.

\section{Author details}

'Division of Nephrology, Department of Medicine, Kurume University School of Medicine, 67 Asahi-machi, Kurume, Fukuoka 830-0011, Japan. ²Department of Nephrology, Yame General Hospital, Yame, Japan. ${ }^{3}$ Moriyama Clinic of Internal Medicine, Asakura, Japan. ${ }^{4}$ Nagata Hospital, Yanagawa, Japan. ${ }^{5}$ Sugi Cardiovascular Hospital, Omuta, Japan. ${ }^{6}$ Department of Nephrology, Yamaguchi Saiseikai General Hospital, Yamaguchi, Japan. ${ }^{7}$ Wada Cardiovascular Clinic, Tosu, Japan. ${ }^{8}$ Usui Clinic, Ukiha, Japan. ${ }^{9}$ Chiba Naika Jyunkankika, Saga, Japan. ${ }^{10}$ Miyazakinaika Medical Clinic, Kurume, Japan. ${ }^{11}$ Department of Biostatistics Center, Kurume University School of Medicine, Kurume, Japan.

Received: 27 July 2020 Accepted: 23 November 2020

Published online: 10 December 2020

\section{References}

1. Moe S, Drüeke T, Cunningham J, Goodman W, Martin K, Olgaard K, et al. Definition, evaluation, and classification of renal osteodystrophy: a position statement from Kidney Disease: Improving Global Outcomes (KDIGO). Kidney Int. 2006;69(11):1945-53.

2. Block GA, Klassen PS, Lazarus JM, Ofsthun N, Lowrie EG, Chertow GM. Mineral metabolism, mortality, and morbidity in maintenance hemodialysis. J Am Soc Nephrol. 2004;15(8):2208-18.

3. Gutiérrez OM, Mannstadt M, Isakova T, Rauh-Hain JA, Tamez H, Shah A, et al Fibroblast growth factor 23 and mortality among patients undergoing hemodialysis. N Engl J Med. 2008:359(6):584-92.

4. Nakai S, Hanafusa N, Masakane I, Taniguchi M, Hamano T, Shoji T, et al. An overview of regular dialysis treatment in Japan (As of December 31, 2012). J Jpn Soc Dial Ther. 2014:1-56

5. Douthat WG, Castellano M, Berenguer L, Guzmán MA, de Arteaga J, Chiurchiu CR, et al. High prevalence of secondary hyperparathyroidism in chronic kidney disease patients on dialysis in Argentina. Nefrologia. 2013; 33(5):657-66.

6. Drüeke TB. The pathogenesis of parathyroid gland hyperplasia in chronic renal failure. Kidney Int. 1995;48(1):259-72

7. Jean G, Bresson E, Terrat JC, Vanel T, Hurot JM, Lorriaux C, et al. Peripheral vascular calcification in long-haemodialysis patients: associated factors and survival consequences. Nephrol Dial Transplant. 2009;24(3):948-55.

8. Faul C, Amaral AP, Oskouei B, Hu MC, Sloan A, Isakova T, et al. FGF23 induces left ventricular hypertrophy. J Clin Invest. 2011;121(11):4393-408.

9. Block GA, Martin KJ, de Francisco AL, Turner SA, Avram MM, Suranyi MG et al. Cinacalcet for secondary hyperparathyroidism in patients receiving hemodialysis. N Engl J Med. 2004;350(15):1516-25.

10. Messa P, Macário F, Yaqoob M, Bouman K, Braun J, von Albertini B, et al. The OPTIMA study: assessing a new cinacalcet (Sensipar/Mimpara) treatment algorithm for secondary hyperparathyroidism. Clin J Am Soc Nephrol. 2008;3(1):36-45.

11. Fukagawa M, Yokoyama K, Shigematsu T, Akiba T, Fujii A, Kuramoto T, et al. A phase 3, multicentre, randomized, double-blind, placebo-controlled, parallel-group study to evaluate the efficacy and safety of etelcalcetide (ONO-5163/AMG 416), a novel intravenous calcimimetic, for secondary hyperparathyroidism in Japanese haemodialysis patients. Nephrol Dial Transplant. 2017:32(10):1723-30.

12. Shigematsu T, Akizawa T, Uchida E, Tsukamoto Y, Iwasaki M, Koshikawa S, et al. Long-term cinacalcet $\mathrm{HCl}$ treatment improved bone metabolism in Japanese hemodialysis patients with secondary hyperparathyroidism. Am J Nephrol. 2009;29(3):230-6.

13. Yokoyama K, Fukagawa M, Shigematsu T, Akiba T, Fujii A, Odani M, et al. A 12-week dose-escalating study of etelcalcetide (ONO-5163/AMG 416), a novel intravenous calcimimetic, for secondary hyperparathyroidism in Japanese hemodialysis patients. Clin Nephrol. 2017:88(2):68-78.

14. Wu B, Melhem $M$, Subramanian $R$, Chen P, Jaramilla Sloey B, Fouqueray B, et al. Clinical pharmacokinetics and pharmacodynamics of etelcalcetide, a novel calcimimetic for treatment of secondary hyperparathyroidism in patients with chronic kidney disease on hemodialysis. J Clin Pharmacol. 2018;58(6):717-26

15. Harada K, Inoue A, Yamauchi A, Fujii A. The pharmacological profile and the clinical efficacy of the world's 1st intravenous calcimimetics; etelcalcetide hydrochloride (Parsabiv). Nihon Yakurigaku Zasshi. 2017;150(2):98-113.

16. Block GA, Bushinsky DA, Cheng S, Cunningham J, Dehmel B, Drueke TB, et al. Effect of etelcalcetide vs cinacalcet on serum parathyroid hormone in patients receiving hemodialysis with secondary hyperparathyroidism: a randomized clinical trial. JAMA. 2017;317(2):156-64.

17. Payne RB, Little AJ, Williams RB, Milner JR. Interpretation of serum calcium in patients with abnormal serum proteins. Br Med J. 1973:4(5893):643-6.

18. Fukagawa M, Yokoyama K, Koiwa F, Taniguchi M, Shoji T, Kazama JJ, et al. Clinical practice guideline for the management of chronic kidney diseasemineral and bone disorder. Ther Apher Dial. 2013;17(3):247-88.

19. Xipell M, Montagud-Marrahi E, Rubio MV, Ojeda R, Arias-Guillén M, Fontseré $\mathrm{N}$, et al. Improved control of secondary hyperparathyroidism in hemodialysis patients switching from oral cinacalcet to intravenous etelcalcetide, especially in nonadherent patients. Blood Purif. 2019:48(2): 106-14.

20. Subramanian R, Zhu X, Hock MB, Sloey BJ, Wu B, Wilson SF, et al. Pharmacokinetics, biotransformation, and excretion of $\left[{ }^{14} \mathrm{C}\right]$ etelcalcetide (AMG 416) following a single microtracer intravenous dose chronic kidney disease on hemodialysis. Clin Pharmacokinet. 2017;56(2):179-92.

\section{Publisher's Note}

Springer Nature remains neutral with regard to jurisdictional claims in published maps and institutional affiliations.

Ready to submit your research? Choose BMC and benefit from:

- fast, convenient online submission

- thorough peer review by experienced researchers in your field

- rapid publication on acceptance

- support for research data, including large and complex data types

- gold Open Access which fosters wider collaboration and increased citations

- maximum visibility for your research: over $100 \mathrm{M}$ website views per year

At $\mathrm{BMC}$, research is always in progress.

Learn more biomedcentral.com/submission 